\title{
Determining Public Structure Crowd Evacuation Capacity
}

\author{
Pejman Kamkarian \\ Computer Engineering Department \\ Southern Illinois University \\ Carbondale, U.S.A
}

\author{
Henry Hexmoor \\ Computer Science Department \\ Southern Illinois University \\ Carbondale, U.S.A
}

\begin{abstract}
This paper explores a strategy for determining public space safety. Due to varied purposes and locations, each public space has architecture as well as facilities. A generalized analysis of capacities for public spaces is essential. The method we propose is to examine a public space with a given architecture. We used Bayesian Belief Network to determine the level of safety and identify points of weakness in public spaces.
\end{abstract}

Keywords - Networks of Bayesian Belief Revision, Public Space Safety, Crowd Evacuation

\section{INTRODUCTION}

Access to geometrics features of a public space as well as crowd specification is essential for exploring the safety of structures. An emergency event requires evacuation of people from indoor spaces. They need to evacuate in the safest possible way within the least amount of time. In an evacuation, the crowd will use spaces and pathways in unintended ways. This stems from collective group behaviors that emerge from an individual's propensity to spend the least amount of effort to vacate the premises. Resulting effects are unpredictable. Although, in some cases, such as attempting to exit through exit doors, minimizing distances to an exit is not a guiding principle; minimizing travel time to reach an exit door might be. Crowd density is important as the number of people in a unit of indoor space, which is not homogenous. Our primary objective is to determine universal factors that can cause collapsing buildings. Secondarily, we wish to develop a model using Bayesian Belief Networks to provide building architects with the capability to examine a public space regarding its capacities to transfer people. This will provide us a metric for quantifying building safety. We hope that our model will be a useful tool that will supplement guidelines for safer future building design codes.

Although no design improvement can prevent disasters, they can mitigate and significantly reduce frequency of occurrence. Our approach is multipronged. We explore crowd specifications as well as building and public space features to suggest a methodology for the design and management of indoor environments where crowds appear. In order to systematically assess risk factors for a building, we must investigate behavior of the crowd dynamics during various situations, such as crowd distribution patterns. The crowd speed of movement, crowd density, and also the space utilization maps allow us to qualitatively and quantitatively assess the safety of the public space. Some physical specifications of indoor public spaces, such as the exit door width or locations of installed ground facilities, are considered as well. For example, the doorway widths should be increased to make crossing through them easier without congestion. Consideration should also be given to the potential usage of interconnected gates called concourses by spectators at events such as public transportation areas. Usage can be considerable if the event spans multiple hours, if inclement weather conditions are present, or if large numbers are in attendance. Development of our pattern spans beyond our current project. The crowd consists of many individuals. Each entity has the capacity to react according to his internal parameters and the specifications of the environment as the simulation proceeds. The dynamics of the crowd are an emergent phenomenon that is not programmed explicitly.

A group of people at an indoor public space may move randomly. Lack of first aid and emergency extinguisher tools will lead to potential disasters in evacuation. In some cases, such as smoke or derbies, the vision is diminished. People mostly try to look for any tools that can help them survive. First aid kits, fire extinguishers or axes, and glowing red exit lights are necessary tools that can expedite evacuation. In this paper we demonstrate the Bayesian Belief Networks as a significant solution to examine and assure the safety for the people. The Bayesian Belief Network performs this task by coalescing general specifications of the environment and the people's behaviors. In section 2 we will describe salient attributes of a crowd. Section 2 outlines crowd attributes as well as physical properties of structures. Section 3 describes Bayesian belief network methodology in general and applies it to a specific building to support our concept. Concluding remarks in section 5 culminate our paper.

\section{PERTINENT PROPERTIES}

Shortcut exploitation is a fundamental human trait that is in effect for crowds. Another relevant property of crowds is competitive behavior, which will become important in egress and ingress conditions. In an evacuation, individuals will compete with one another in progressing towards exits, exploiting optimal available paths. Our tool will be a predictive device for discovering human characteristics affecting unsafe movement patterns in public spaces. Whereas guiding principles encode salient properties and behaviors, they can 
hinder intended results for evacuation. Our system is used to propagate microscopic human behaviors, such as movement and distributions, in different situation to discover emergent properties. It will replace the previous macroscopic analyses that do not scale up well. By studying geometric information of indoor structures, we can consider layouts that lower redundant movements. This will allow us to assess realistic room capacity distribution in a space. In this study we have limited our scope to static spaces with dynamic, fluid-like crowd movement. Crowds do not fill a space uniformly. Instead, they cluster; they exploit short cuts; they flock, and they exhibit herding behavior as in sheep movement. Once committed to a route, we cannot alter their paths by static signs. It is conceivable that an overhaul of safety guidelines is required for improved designs. One of the key features to prevent hazardous situations is to consider and design evacuation strategies, which continually attract crowds. Every building typically has established operational evacuation policies during emergency egress. However, often these policies are not adequately tested until a real crisis occurs. Therefore, the problem is in anticipating problems that may occur during an emergency. If the design could be constructed in advance, it would be possible to perform qualitative and quantitative risk assessments by destructive testing. Unfortunately, in most cases there is not a mechanism to fully test all emergency contingencies for a specific building. People will always try to find a safe and fast way to leave dangerous positions. Investigating human behaviors and the pertinent building's physical specifications are the focal aims of this research. In order to predict a pattern of gathering people in a location, general knowledge of the public space is essential. The location of public space is important information that can help us predict gathering patterns. Some public spaces have more capacity to allow people to move and gather at the place. We need to consider obstacles that are normally affixed in the environment because they can often affect the crowd distribution patterns. A key feature for consideration is facilities that are installed inside for use by people such as vending machines or stages. We need to consider geographic location of the environment and also the kind of buildings or floors that exist around the space. We will discuss each of these features in the constructing of Bayesian belief networks section.

\section{BAYESIAN BELIEF NETWORKS (BBN)}

Humans are able to distinguish relations among features of general attributes, such as skin colors and their values for each such as Asians and Europeans [8]. Two general types of such attributes include: near-deterministic and probabilistic. Near-deterministic attributes are those that are related to geographic details, such as skin color and birth place. All other kinds of relations that are not deterministic are classified as probabilistic. As an example for near-deterministic, we might point to a child who was born in an Asian country. Such a child usually has the same skin color as his parents. A person with darker skin, who lives in Africa, doesn't necessarily speak or even know how to speak African. We consider these kinds of examples in the probabilistic category. Bayesian belief network is a probabilistic graphical pattern consisting of a set of random variables as well as their conditional dependencies that can be shown as a directed acyclic graph. A Bayesian belief network consists of a set of nodes that are connected to each other through directed lines called edges. Each node may have a set of parents as well as children. There may be some nodes without having any parents in a BBN tree. We called such nodes initial nodes. In order to obtaining the status of child nodes determining the initial nodes are essential. Instead of focusing on all possible dependencies among attributes, BBN concentrates and examines only the significant dependencies among all attributes in the domain. BBN produces a compact representation of joint probability that is distributed among all attributes. In terms of developing a new Bayesian belief networks we seek the most parsimonious and yet the most complete graph. In such a graph, each variable is conditionally independent of any combination of its parent nodes [14]. Each node has its own conditional probability table (CPT), which consists of all possible states based on all possible states of its parent nodes. For those nodes without any parent we will use unconditional probabilities table. The problem of discovering existing inter-connected networks is NP-hard [6]. Bayesian belief network was called belief networks in the beginning [32]. Later it was developed and studied diversely. It was called by several different names such as causal nets [17], probabilistic causal networks [5], probabilistic influence diagrams [20], [37], and probabilistic cause-effect models [36]. At the early stages of use it was applied to simple methods, such as medical diagnostics. For example, an earliest usage was as a technical aid to support medical experts by applying to a database, which consisted of different symptoms and related diseases. It was supposed to predict the kind of disease based on brief details for the observed symptoms [1]. Microsoft announced cited its competitive advantages with its expertise on Bayesian belief networks [18]. To present further examples of future usage of BBN, we can point to robot help and guidance [3], software reliability assessment [30], data compression [14], and fraud detection [13]. Probabilistic reasoning and Bayesian belief networks are widely used to predict behaviors in many computational systems such as in [41] that produced robotic navigation routes amongst crowds using the least probabilistic obstructed regions in dense crowds. This is solving a classic robotic slow decision making problem. Probabilistic evacuation of a crowd escaping fire is simulated in [35] where human cognitive processes are modeled. A good survey of common crowd modeling and simulation techniques is found in [38]. Using Bayesian belief networks for customizing products leads to building a product based on the customer's needs. There are several applications that represent the probabilistic relationships between different attributes using a directed graph in the area of artificial intelligence [11], [42]. Bayesian belief networks became acceptable and popular among artificial intelligence communities as a solution to represent uncertain knowledge, in the late 1980's [26], [33]. Today, Bayesian belief networks are widely applied to different sciences such as expert systems and diagnostic systems.

Each Bayesian belief network is a collection of joint 
probability distributions. It consists of two different concepts: a directed acyclic graph $G$ and a conditional distribution for each child variable in the graph $G$. The Bayesian belief network graph nodes represent random variables such as $\left\{V_{1}, V_{2}, \ldots, V_{n}\right\}$. We assume $\beta$ to show conditional distribution for each child variable that is available in graph $G$. Combining the graph nodes and their distribution leads to having a unique distribution on the set of variables such as $\left\{V_{1}, V_{2}, \ldots, V_{n}\right\}$. Each child variable $V_{i}$ only belongs to its parent nodes as its descendents. For each individual child variable in graph $G$ we have the following equation 1 :

$$
P\left(V_{i} \mid \operatorname{Par}^{G}\left(V_{i}\right)\right)
$$

Where $\operatorname{Par}^{G}\left(V_{i}\right)$ are parent nodes of the variable $V_{i}$ in graph $G$. consideration of probabilities and properties of conditional independencies rules, we can rewrite the equation 1 as the following equation 2 :

$$
P\left(V_{1}, V_{2}, \ldots, V_{n}\right)=\prod_{i=1}^{n} P\left(V_{i} \mid \operatorname{Par}^{G}\left(V_{i}\right)\right)
$$

Figure 1 represents a simple Bayesian belief network graph $G$ consisting of four nodes:

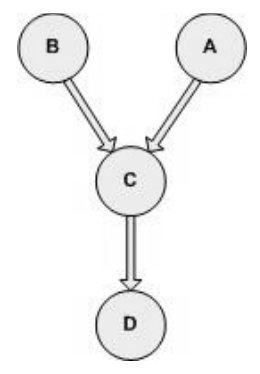

Figure 1. A simple Bayesian belief network graph $G$ consisting of four nodes

Based on the graphical structure of the graph shown in figure 1, the following conditional independencies are available:

$$
I(A ; B), I(C \mid A, B), I(D ; A, B \mid C), I(B ; A)
$$

The following equation 3 represents the joint distribution of graph $\mathrm{G}$ shown in figure 1 into the product form:

$$
P(A, B, C, D)=P(A) P(C \mid A, B) P(D \mid C) P(B)
$$

The way of representing conditional distribution is varied based on the type of variable. We may have discrete variables, continuous variables or a combination of both. In case of having discrete variables from a finite set of variables, we can represent conditional distribution at a table that shows the probability values for $V_{i}$ for each joint relationships into the present set, $\left\{\mathrm{Par}_{1}, \mathrm{Par}_{2}, \ldots, \mathrm{Par}_{n}\right\}$. If the variables and their parent nodes are in real values, there is no way to show all their possible densities. In such cases we may use Gaussian distribution rules as a solution. The following equation 4 shows linier Gaussian conditional densities that are applied to a variable given its parents nodes:

$$
P\left(\operatorname{VIpar}_{1}, \operatorname{par}_{2}, \ldots, \operatorname{par}_{n}\right) \sim N\left(a_{0}+\sum_{i} a_{i} \times \operatorname{par}_{i}, \partial^{2}\right)
$$

Where $V_{i}$ is a normally distribution around a mean point that linearly depends on the values of its parents nodes. $\partial^{2}$ as the variance of normal distribution is also independent of the parent nodes set. If all existing child variables in graph $G$ have linear Gaussian conditional distribution, the joint distribution will become a multivariate Gaussian form [27].

When the graph $G$ consists of a combination of both discrete child variables with continued parent nodes and continued child variables with discrete parent nodes at a same structure, then we will use two methods to represent distributions. For those discrete child variables with continued parent nodes, we use integral of Gaussian distribution to show the probability distribution, while for continued child variables with discrete parent nodes, we use conditional Gaussian distribution to show probability distribution [27].

\section{A. KEY FEATURES}

Bayesian belief networks have many important key features, such as explaining away, which means changing beliefs by considering and applying all possible information; Bi-directional graph, which means evaluating and diagnosing performances bottom up; complexity, which means being able to apply and use for complicated models; uncertainty, which means having the ability to be applied in environments having uncertain data; readability, which means having a simple graphical and transparent structure in terms of being able to be interpreted easily by humans; prior knowledge, which means the ability to coordinate and apply to expert knowledge; and confidence values, which means providing a confidence measurements on possible results. As we proceed through this section, we will explain each of the above mentioned key features of Bayesian belief network models.

\section{Explaining away}

In the case of observing alternative explanations which can cause change in the belief for a current explanation, we have an explaining away [24]. For example, if shutting off the lights occurred, it may lead our beliefs into two different reasons: the house's fuse box has a problem with the main fuse box of the area. In this case our belief in any of the mentioned explanations will increase. By observing when the other neighbor's lights are off, it deduces that the main fuse box of the area has a problem, and it is not limited to the interior house. In this case, because we believe that the 
shutting off of the lights is because of a failure in the area, there are no reasons to believe that a failure exists inside the house, and hence we should retract that belief [21].

\section{Bi-directional structure}

$\mathrm{Bi}$-directional is an ability to predict the inputs based on a certain output. For example, in case of producing cars, a Bayesian belief network is able to give us the features necessary to produce each customized car. In other words, it is able to show us the inputs based on a specific output. Such ability isn't available for many other intelligent systems, such as fussy logic and feed forward neural networks. The mentioned systems are called one-way models, or in other words, from input to output only and hence trace the inputs based on a certain output is impossible.

\section{Complexity}

Bayesian belief network consists of a set of nodes, and arcs between nodes. Each node may have many children nodes or parent nodes. Because the probability distribution of attributes for each certain value depends only on its parents nodes, estimation is possible based on fewer parameters. In other words, because each node and its parents are separated from the rest of model; we need fewer parameters in terms of being able to predict the kind of relationships between different variables.

\section{Uncertainty}

Assume having a group of people who are gathered at a same place for a party. Predicting the time, the path, and the next favorite location inside the environment for any available individual at any certain time is almost impossible. Each individual chooses his/her path, location and the time of movement based on his/her needs. There are a variety of reasons of existence uncertainty, such as distortion, irrelevancy, and incompleteness [24]. In such cases in Bayesian belief networks, we use probabilities, rather than certain values such as true or false. This means Bayesian belief networks are able to apply to cases where a combination uncertainty is much more desirable.

\section{Readability}

As a main key feature of Bayesian belief networks, we can point to readability. This means it has a simple and easy to recognize model even for complicated problems. Having a graphical structure pattern of Bayesian belief networks, using simple meanings such as nodes and arcs between nodes, and having a rational organizing and designing variables and the relations between variables, make the Bayesian belief networks a pleasant solution to apply complex problems that are involved with many different relations and nodes. In other words, applying Bayesian belief networks to a complex problem consisting of a lot of different relations and nodes won't reduce its easy interpretability by humans because of its graphical and rational structure.

\section{Prior knowledge}

In order to design each model, having basic values and measurements are essential. In Bayesian belief networks, in order to design the model, we need to have only formal initial values rather than broad different values and limitations for each one. Having such ability as another main key feature of Bayesian belief networks makes it more meaningful to apply to a variety of problems, especially on models for which we don't have broad initial values or prior data knowledge about.

\section{Confidence values}

In many intelligent systems such as neural networks, the prediction results in a vector or scalar value which is not suitable enough in case of needing to have a decision maker system. Instead, in Bayesian belief networks, because of having a probability distribution which is a boundary between a law and high value, we are able to build a decision support system more efficiently.

\section{B. THEORY}

In order to design a model of Bayesian belief networks, we need to investigate three different areas: general structure definition, parameters definition, and using the created model to start predicting.

\section{General structure definition}

A Bayesian belief network generally consists of two parts: nodes that represent values and bi-directed arcs that show relations between nodes. The simplest case of Bayesian belief networks consist of a node as child which has one parent node and a bi-directed arc which is located between the child node and the parent node. In the case of a real problem, we may have a large group of nodes and bi-directed arcs as relations between them. In such models, tracing and finding a certain parameter among a large group of nodes and relations may take a long time and will significantly reduce the performance of the Bayesian belief network. As a solution to this problem, we may use a search technique in order to increase the quality and reduce the needed time to trace and find any certain parameter. Many different search techniques have the ability to apply a Bayesian belief networks models, such as K2 methods that were proposed by Cooper and Herskovits [7]. This algorithm is able to trace and find the parameters for certain nodes based on a greedy search algorithm; Generic algorithms may be used to ordering nodes for using by K2. structural search of this algorithm is similar to the travelling salesman problem [25], [12], and modified Expectation Maximization (EM) method [15], which can learn the available general structure and parameters in Bayesian belief networks model and branch and bound method [29]. It is able to limit the combinatorial explosion for example during choosing a certain feature.

Parameters definition 
The next step to designing Bayesian belief networks model is defining conditional probabilities for each node. In other words, we need to determine the estimation of occurrence for each node, where can be considered by a set of nodes as well as their parent nodes. One way to estimate the probability is to use the frequency of occurrence for each set of variables among available data. If the number of times observation increases, the frequency tends toward a true probability distribution. In case of having a small set of data, using an alternative approach is essential. Based on that we need initially to assume a particular distribution such as uniform and then update it in order of encapsulation the information contained among available data. To achieve this goal, we may use Expectation Maximization (EM) algorithm [9], which can be combined with an equivalent sample size [28].

\section{Using the created model to start predicting}

As the final step, we have to use the final model in terms of making prediction. In case of observing some values of some variables we are able to calculate the remaining variables. To achieve this goal, we need to find the states of observations and then propagating the beliefs around the available networks, and continue this until all beliefs that are in the form of conditional probabilities become consistent. Finally we can read the favorite probability distribution directly from the Bayesian belief networks.

\section{CONSTRUCTING OF BAYESIEN BELIEF NETWORKS}

In order to implement and demonstrate our Bayesian belief network, we considered two separate work areas: indoor public space specifications, including both indoor and some outdoor, and the features of people who are presented on the public space. We then applied both indoor public space and the people features on a unit Bayesian belief networks pattern.

\section{A. IMPLEMENTATION}

Generally we have divided the employed factors of a building safety crowd evacuation into two categories including Physical public space specifications, and the Crowd specifications itself.

\section{Physical properties}

Studding on physical properties, while investigating on crowd safety evacuation is essential. Most of time, people are located in a closed covered area when gathering for any certain event. They share a common activity which is almost related to the reason of gathering while forming a crowd. Of all existing features that may directly or indirectly are related to the geometric indoor space details, the following were more interested with us to be considered:

Terrestrial sustainability: We considered on any natural or other sources that can cause vibrating the indoor space as an important factor. There are two general sources that can affect a public space to be vibrating. In terms of determining the safety of the building, considering to such sources is essential. The first group of sources is natural and is related to the area geometry specifications that a public space is built on; such as the distance from any faults or volcanoes. The second group of vibrating sources may create by human such as any metro or train facilities. Beside the mentioned reasons, considering the average weather status of the area is one other key feature that can affect the rate of vibrating the construction significantly. A public space located in a severe area that has stormy weather most times a year is more expose to be vibrated than the one which is located in an area with having a stable weather.

Flow capacity: We divided this feature into two categories: the flow capacity for interior public space and for the building that the examined public space is located inside. For indoor public space, we focused on obstacles in terms of the number, installation positions and also the average size of them. Each public space has a number of emergency exit doors as well as normal entrances that should be taken into account. To have an estimation of safety for general building flow capacity, we considered on all existence obstacles that are located somewhere between the indoor space and the main entrances of the building. The number of such objects, as well as the installation positions and the average size of them were the factors that we considered for this category. As another key feature, we investigated on the type of the building such as a flat, an apartment, a tower and so on. In case of being inside an apartment or a tower, considering the level that public space is located leads having a better estimation for the evacuation safety rate.

Overall exit capacity: Each door, based on its location, and the width, has a different ability to allow passing a number of people trough it at any moment. We considered this feature for not only the examined public space, but for all entrance that are located between indoor space and the main building.

First Aid recovery capacity: In emergency cases, having a proper distinguisher tools that are installed on a reasonable locations can help people to stay alive and safe in a more period of time before being able to evacuate from dangerous situations. For example; in case of firing, using existing fire distinguishers near the incident, help people to stay alive inside the area of fire for longer time before evacuating while a large group of people tend to across from entrances.

Structural integrity: To have a better building safety estimation, considering the materials that public space is made of as well as the year of build is essential.an old age building, especially in case of using old materials may leads putting the people inside at higher risk that a new building consisting a new and better materials.

Space occupancy rate: This factor can be determined by 
the type of using the public space as well as the shape and the variety of installed facilities inside. A theater or a conference room which has variety rows of chairs may allow more people at any moment than a storage room or an area consist a sort of different offices.

\section{Crowd properties}

Considering on movement rate, which is related on the average age of the crowd as well as their average health status, and distribution pattern for each moment leads us having a better estimation of crowd evacuation safety rate. As we observe in a kindergarten, the average of majority age is below 10 years old, while in a conference room, it is above it. In a hospital, as another instance, the average health status is weak, while is a sport complex saloon, it is good.

\section{B. NETWORK TOPOLOGY}

We focused and classified all factors as the important key features addresses in the previous section, to build our Bayesian belief network structure. The proposed pattern may be varied when considering different areas with having different situations. The topology of the general BBN network consists of many sub trees.

As the central part of $\mathrm{BBN}$ tree, figure 2, shows the general nodes that lead to the public safety. The conditional probability table (CPT) as well as attributes of each nodes are as follows. In each table, the value of 0.6 or greater than that for safety indicates a safe situation as the result of the obstacles node. The values of 0.4 or larger, for safety situation of each parent node, on the tables, show a safe node for it.

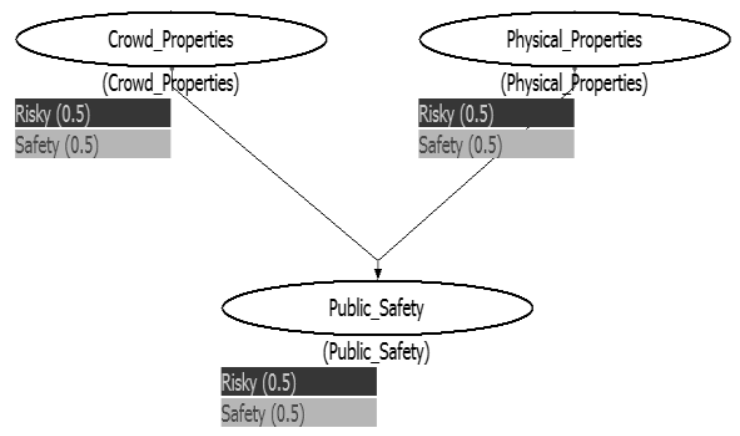

Figure 2. General BBN pattern

- Public_Safety (A) : Safety (S), Risky (R)

- Crowd_Properties (B) : Safety (S), Risky (R)

- Physical_Properties (C) : Safety (S), Risky (R)

Table 1, shows all probability all conditions of nodes B and $\mathrm{C}$ along with their child node $\mathrm{A}$.

\begin{tabular}{|c|c|c|c|}
\hline \multicolumn{4}{|c|}{$\mathrm{P}(\mathrm{A} \mid \mathrm{B}, \mathrm{C})$} \\
\hline B & $\mathrm{C}$ & $\mathrm{S}$ & $\mathrm{R}$ \\
\hline $\mathrm{S}$ & $\mathrm{S}$ & 0.9 & 0.1 \\
\hline $\mathrm{S}$ & $\mathrm{R}$ & 0.5 & 0.5 \\
\hline $\mathrm{R}$ & $S$ & 0.5 & 0.5 \\
\hline $\mathrm{R}$ & $\mathrm{R}$ & 0.1 & 0.9 \\
\hline
\end{tabular}

Table 1. The CPT for General_Public_Safety_Rate

\section{Physical properties}

This node is a general parent node, which obtains its value, by considering many other general nodes. As a parent node, it has many other child nodes that each of them has their own dependencies. The following are this node's child nodes: Terrestrial sustainability, Flow capacity, Overall exit capacity, Space occupancy rate, First aid recovery capacity, and Structural integrity.

Figure 3, shows this node with its child nodes in a BBN network pattern. Because this part of BBN tree has 64 different combinations, we represented its CPT table into a diagram as shown in Diagram 1. The combinations set of the parent nodes are as : $\{(B, C, D, E, F, G)\}$, or as the following set with details

$\{(S, S, S, S, S, S),(S, S, S, S, S, R), \ldots,(R, R, R, R, R, R)\}$.

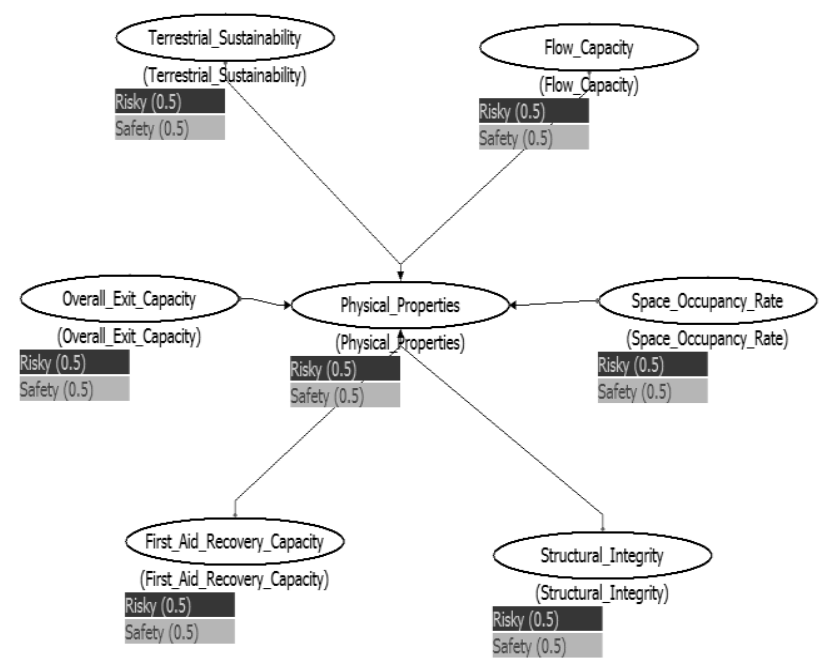

Figure 3. Physical properties node with its child nodes

- Physical_Properties (A) : Safety (S), Risky (R)

- Flow_Capacity (B) : Safety (S), Risky (R)

- Space_Occupancy_Rate (C) : Safety (S), Risky (R)

- Structural_Integrity (D) : Safety (S), Risky (R)

- First_Aid_Recovery_Capacity (E) : Safety (S), Risky

(R)

- Overall_Exit_Capacity (F) : Safety (S), Risky (R)

- Terrestrial_Sustainability (G) : Safety (S), Risky (R) 


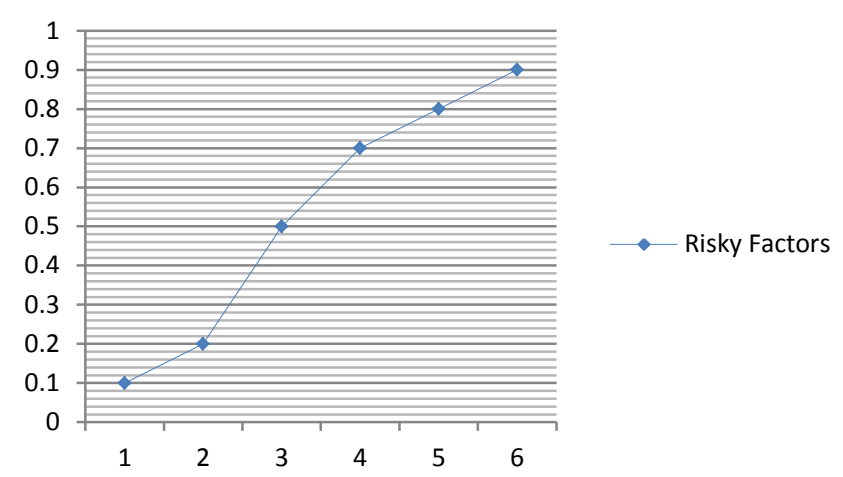

Diagram 1. The CPT diagram for Physical_Properties node

Diagram 1 shows risky factors to rate proportions. For example, with one risky situation among all other values converts the final result as 0.1 chance of risky, or in the other hand, it is $90 \%$ chance of safety. Each node in BBN tree has its own conditional probability table (CPT). Each table has two entities, including Safety and Risky, that show a value based on the indoor public situation in percentage. As initialize, both of their values as set as 0.5 which means having a normal situation. We demonstrate each of its child nodes in details as follows.

Terrestrial sustainability: This node can be in safe situation, if the average value of all its children shows either normal or in a low risk situation. This node has three children as follows:

Terrain instability sources distance: Based on the distance of any natural vibration sources, such as earth faults or volcanoes, a value in percentage will assign to this node. If the public space is 50 kilometers far from any earth faults or volcanoes, we considered this node as a safe node.

Manmade instability sources: The distance from examined public space to any human made vibrating sources such as train rails or metro tunnels is the target to measures this node's value. The lower rate means unsafely situations that indicated a close distance to such sources, while a higher value shows a longer distance from any unnatural vibrating sources. Locating at a distance of 3 kilometers or less, leads it has a risky value.

Weather instability sources: This node can be determined by the total average weather of the area that the public space is located on. A windy or stormy area results having a risky status and hence a lower value in percentage, while for areas with a stable weather, this node employ a higher value which means locating in a safe location in terms of the average weather situation.

Figure 4, shows this node, with its child nodes.

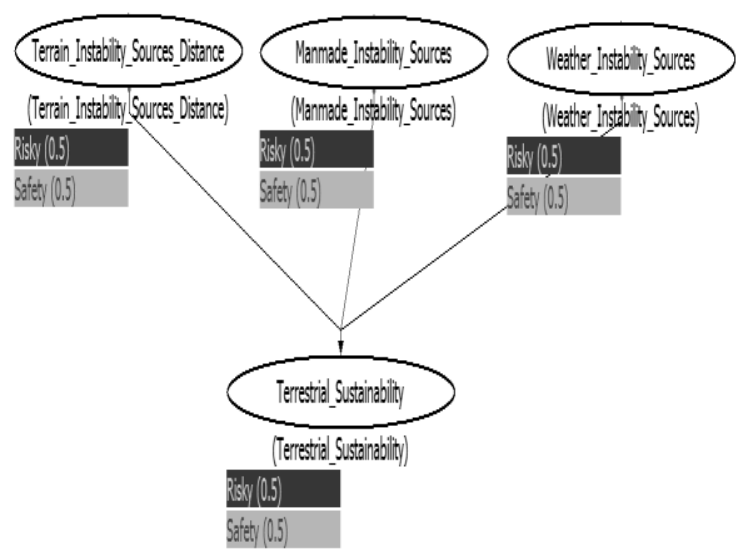

Figure 4. BBN for Terrestrial Sustainability node

- Terrestrial_Sustainability (A) : Safety (S), Risky (R)

- Terrain_Instability_Sources_Distance (B) : Safety (S), Risky (R) (R)

- Manmade_Instability_Sources (C) : Safety (S), Risky

- Weather_Instability_Sources (D) : Safety (S), Risky (R)

Table 2, shows all probability all conditions of nodes B, C, and $\mathrm{D}$ along with their child node $\mathrm{A}$.

\begin{tabular}{|c|c|c|c|c|}
\hline \multicolumn{5}{|c|}{$\mathrm{P}(\mathrm{A} \mid \mathrm{B}, \mathrm{C}, \mathrm{D})$} \\
\hline $\mathrm{B}$ & $\mathrm{C}$ & $\mathrm{D}$ & $\mathrm{S}$ & $\mathrm{R}$ \\
\hline $\mathrm{S}$ & $\mathrm{S}$ & $\mathrm{S}$ & 0.9 & 0.1 \\
\hline $\mathrm{S}$ & $\mathrm{S}$ & $\mathrm{R}$ & 0.7 & 0.3 \\
\hline S & $\mathrm{R}$ & $\mathrm{S}$ & 0.7 & 0.3 \\
\hline S & $\mathrm{R}$ & $\mathrm{R}$ & 0.5 & 0.5 \\
\hline R & S & S & 0.7 & 0.3 \\
\hline R & S & R & 0.5 & 0.5 \\
\hline R & R & S & 0.5 & 0.5 \\
\hline R & R & R & 0.1 & 0.9 \\
\hline
\end{tabular}

Table 2. The CPT for Terrestrial_Sustainability

Overall exit capacity: In case of considering this node as a parent node, it consists of two child nodes: Building interior evacuation rate and Building perimeter evacuation rate. Figure 5, shows this node as the parent node, including its child nodes in general. 


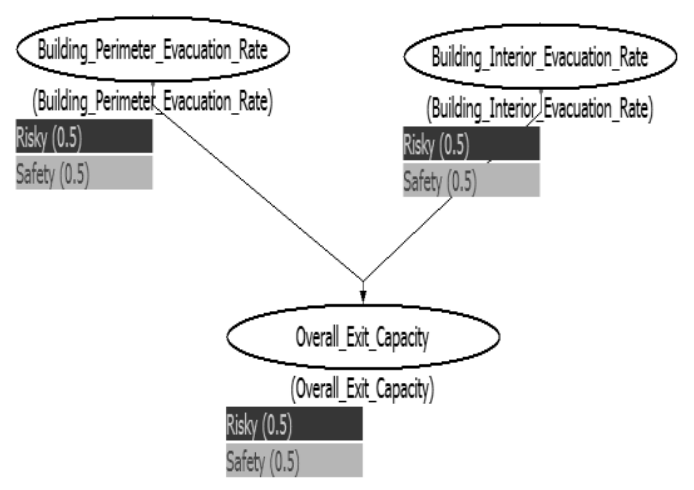

Figure 5. General BBN for Overall exit capacity node

- Overall_Exit_Capacity (A) : Safety (S), Risky (R)

- Building_Perimeter_Evacuation_Rate (B) : Safety (S), Risky (R)

- Building_Interior_Evacuation_Rate (C) : Safety (S), Risky (R)

Table 3, shows all probability all conditions of nodes B and $\mathrm{C}$ along with their child node $\mathrm{A}$.

\begin{tabular}{|c|c|c|c|}
\hline \multicolumn{4}{|c|}{$\mathrm{P}(\mathrm{A} \mid \mathrm{B}, \mathrm{C})$} \\
\hline $\mathrm{B}$ & $\mathrm{C}$ & $\mathrm{S}$ & $\mathrm{R}$ \\
\hline $\mathrm{S}$ & $\mathrm{S}$ & 0.9 & 0.1 \\
\hline $\mathrm{S}$ & $\mathrm{R}$ & 0.5 & 0.5 \\
\hline $\mathrm{R}$ & $\mathrm{S}$ & 0.5 & 0.5 \\
\hline $\mathrm{R}$ & $\mathrm{R}$ & 0.1 & 0.9 \\
\hline
\end{tabular}

Table 3. The CPT for Overall_Exit_Capacity

The building perimeter evacuation rate has three child nodes itself; Obstacles, Type of building and Floor level Vertical_Distance. Obstacle consists of three other children nodes, including; Number of obstacles, Average size of obstacles, and Obstacle impasse rate. We classified some objects that are normally available at any public places, such as trash cans as the obstacles. The number of available obstacles will be determine by value of this node which can be a number between 0 , that represent availability numerous kinds of different obstacles, to 100 which indicates having a few obstacles, or obstacles that are located in proper locations. If the result of this node becomes greater than 40 , we consider it as safety. The node of Size of obstacles increases by the condition of having obstacles with less average sizes inside the public place. In other term, if the value of this node is closing to 100 , it means that we have obstacles having small sizes in average. The value greater than 40 indicates a safety situation. Based on the locations that obstacles may have, the Obstacle impasse rate node will employ a value. Having a larger value indicates existing obstacles in proper safe locations in terms of preventing causing any potential risks for people while evacuating during any emergency situations. Value of 40 or greater, shows a safety situation for this node. Having a value, greater than 0.6 , indicates a safety situation for the obstacle safety node. Figure 6, shows the BBN network for building evacuation rate.

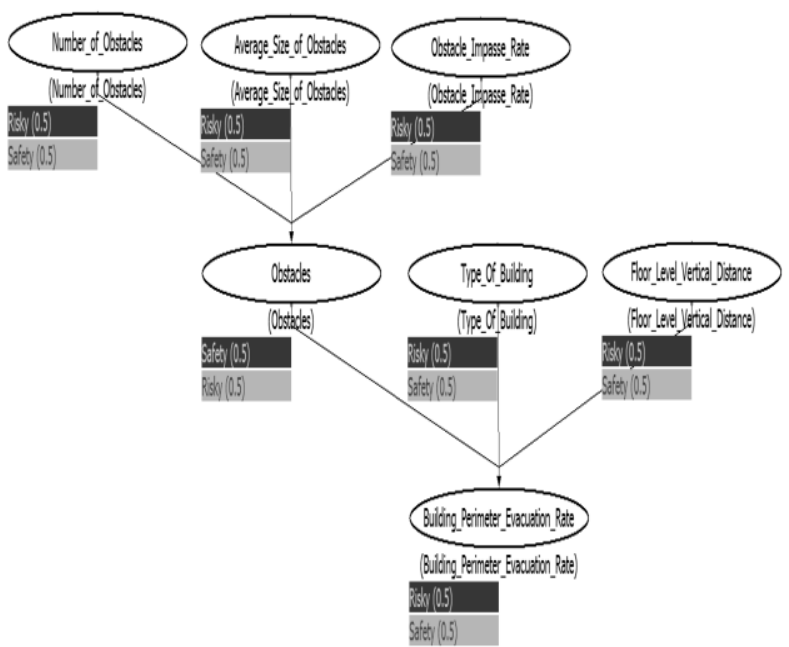

Figure 6. Building perimeter evacuation rate BBN tree

In order to show conditional probability tables for figure 6 , we divided its BBN tree into two different sub trees, as follows:

Sub tree 1:

- Obstacles (A) : Safety (S), Risky (R)

- Number_of_Obstacles (B) : Safety (S), Risky (R)

- Average_Size_of_Obstacles (C) : Safety (S), Risky (R)

- Obstacle_Impasse_Rate (D) : Safety (S), Risky (R)

Table 4, shows all probability all conditions of nodes B, C, and $\mathrm{D}$ along with their child node $\mathrm{A}$, related to the first sub tree:

\begin{tabular}{|c|c|c|c|c|}
\hline \multicolumn{5}{|c|}{$\mathrm{P}(\mathrm{A} \mid \mathrm{B}, \mathrm{C}, \mathrm{D})$} \\
\hline B & $\mathrm{C}$ & $\mathrm{D}$ & $\mathrm{S}$ & $\mathrm{R}$ \\
\hline $\mathrm{S}$ & $\mathrm{S}$ & $\mathrm{S}$ & 0.9 & 0.1 \\
\hline $\mathrm{S}$ & $\mathrm{S}$ & $\mathrm{R}$ & 0.7 & 0.3 \\
\hline $\mathrm{S}$ & $\mathrm{R}$ & $\mathrm{S}$ & 0.7 & 0.3 \\
\hline $\mathrm{S}$ & $\mathrm{R}$ & $\overline{\mathrm{R}}$ & 0.5 & 0.5 \\
\hline $\mathrm{R}$ & $S$ & $\mathrm{~S}$ & 0.7 & 0.3 \\
\hline $\mathrm{R}$ & $\mathrm{S}$ & $\mathrm{R}$ & 0.5 & 0.5 \\
\hline $\mathrm{R}$ & $\mathrm{R}$ & $\mathrm{S}$ & 0.5 & 0.5 \\
\hline $\mathrm{R}$ & $\mathrm{R}$ & $\mathrm{R}$ & 0.1 & 0.9 \\
\hline
\end{tabular}

Table 4. The CPT for Obstacles

Sub tree 2:

- Building_Perimeter_Evacuation_Rate (A) : Safety (S), Risky (R)

- Obstacles (B) : Safety (S), Risky (R)

- Type_Of_Building (C) : Safety (S), Risky (R)

(R)

- Floor_Level_Vertical_Distance (D) : Safety (S), Risky

Table 5, shows all probability all conditions of nodes B, C, 
and $\mathrm{D}$ along with their child node $\mathrm{A}$, related to the second sub tree:

\begin{tabular}{|c|c|c|c|c|}
\hline \multicolumn{5}{|c|}{$\mathrm{P}(\mathrm{A} \mid \mathrm{B}, \mathrm{C}, \mathrm{D})$} \\
\hline $\mathrm{B}$ & $\mathrm{C}$ & $\mathrm{D}$ & $\mathrm{S}$ & $\mathrm{R}$ \\
\hline $\mathrm{S}$ & $\mathrm{S}$ & $\mathrm{S}$ & 0.9 & 0.1 \\
\hline $\mathrm{S}$ & $\mathrm{S}$ & $\mathrm{R}$ & 0.7 & 0.3 \\
\hline $\mathrm{S}$ & $\mathrm{R}$ & $\mathrm{S}$ & 0.7 & 0.3 \\
\hline S & $\mathrm{R}$ & $\mathrm{R}$ & 0.5 & 0.5 \\
\hline $\mathrm{R}$ & $\mathrm{S}$ & $\mathrm{S}$ & 0.7 & 0.3 \\
\hline $\mathrm{R}$ & $\mathrm{S}$ & $\mathrm{R}$ & 0.5 & 0.5 \\
\hline $\mathrm{R}$ & $\mathrm{R}$ & $\mathrm{S}$ & 0.5 & 0.5 \\
\hline $\mathrm{R}$ & $\mathrm{R}$ & $\mathrm{R}$ & 0.1 & 0.9 \\
\hline
\end{tabular}

Table 5. The CPT for Building_Perimeter_Evacuation

Floor level vertical distance: If public space is located at the ground level of the building, or there is no other floors are exist at the top of the bottom of the space, this node will have a higher value, while locating in a upper floors of an apartment or a tower, result the value to have a smaller value. The value of this node represents the degree of easy evacuating and reaching to the final building exits while have an emergency situation. If public space is located at the first floor, we consider this node as safe; otherwise it has a risky value.

Type of building: We considered the type of the building as an important key feature that can affect the general building safety rates. The single house of a building with a single floor has a better chance for its people to evacuate from it in a reasonable time than locating in a tower that has many different public spaces with many groups of people inside of each. If the value of this node owed a higher rate, means the public space is safe enough to evacuate in terms of interrupting with other public spaces that may available inside the building. The following conditions lead this node become as a safe node. Otherwise we consider it as a risky node.

- Locating public space in the first floor,

- Locating at a flat building with no floors.

Building interior evacuation rate: To determine the value of this node, values of its three child nodes including Total number of exit doors, Total number of normal doors, and Obstacles should be determined. For areas having more exit doors as well as normal entrances, there is a higher chance to evacuate people in emergency cases. Increasing the number of exit doors and all other type of entrance, result to raise the value of the relative nodes which indicates having a lower risk and hence more safety inside the public space.

Obstacles: Similar the general building, we considered on the different obstacles that might be available inside the public space. The total average size, as well as the number, and the installation positions are important factors that can affect the obstacles node value, and hence indoor evacuation rate node value. If obstacles occupied more than $40 \%$ of the whole available space, we consider relevant nodes as risky.

Figure 7, shows this node, with its child nodes in BBN pattern.

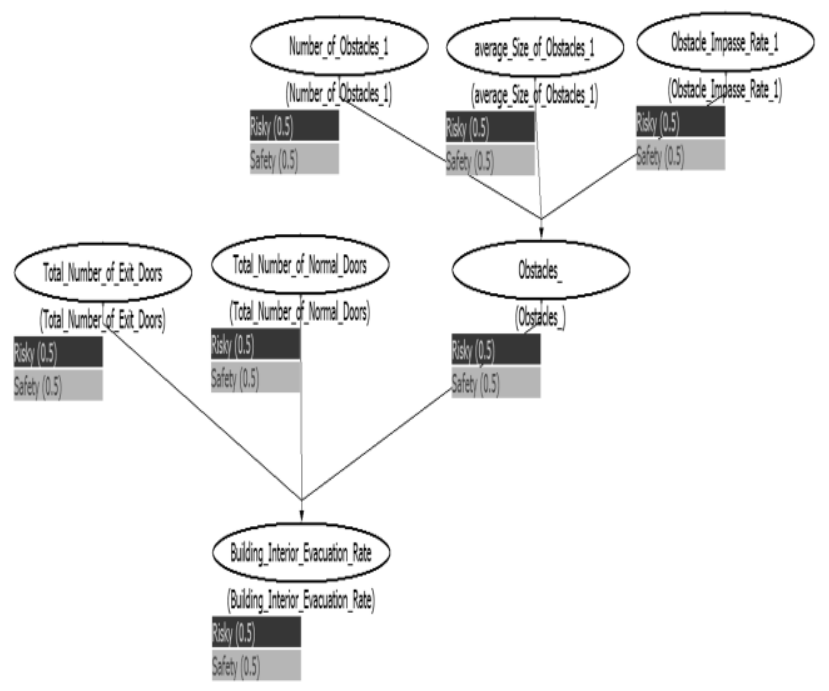

Figure 7. BBN network for Building interior evacuation rate node

In order to show conditional probability tables for figure 7 , we divided its $\mathrm{BBN}$ tree into two different sub trees, as follows:

Sub tree 1:

- Obstacles (A) : Safety (S), Risky (R)

- Number_of_Obstacles (B) : Safety (S), Risky (R)

- Average_Size_of_Obstacles (C) : Safety (S), Risky (R)

- Obstacle_Impasse_Rate (D) : Safety (S), Risky (R)

Table 6, shows all probability all conditions of nodes B, C, and $\mathrm{D}$ along with their child node $\mathrm{A}$, related to the first sub tree:

\begin{tabular}{|c|c|c|c|c|}
\hline \multicolumn{5}{|c|}{$\mathrm{P}(\mathrm{A} \mid \mathrm{B}, \mathrm{C}, \mathrm{D})$} \\
\hline $\mathrm{B}$ & $\mathrm{C}$ & $\mathrm{D}$ & $\mathrm{S}$ & $\mathrm{R}$ \\
\hline $\mathrm{S}$ & $\mathrm{S}$ & $\mathrm{S}$ & 0.9 & 0.1 \\
\hline $\mathrm{S}$ & $\mathrm{S}$ & $\mathrm{R}$ & 0.7 & 0.3 \\
\hline $\mathrm{S}$ & $\mathrm{R}$ & $\mathrm{S}$ & 0.7 & 0.3 \\
\hline S & $\mathrm{R}$ & $\mathrm{R}$ & 0.5 & 0.5 \\
\hline $\mathrm{R}$ & $\mathrm{S}$ & $\mathrm{S}$ & 0.7 & 0.3 \\
\hline R & $\mathrm{S}$ & $\mathrm{R}$ & 0.5 & 0.5 \\
\hline R & $\mathrm{R}$ & $\mathrm{S}$ & 0.5 & 0.5 \\
\hline $\mathrm{R}$ & $\mathrm{R}$ & $\mathrm{R}$ & 0.1 & 0.9 \\
\hline
\end{tabular}

Table 6. The CPT for Obstacles

Sub tree 2: Risky (R)

- Building_Interior_Evacuation_Rate (A) : Safety (S), (R) 
Risky (R)

- Total_Number_of_Normal_Doors (C) : Safety (S),

- Obstacles (D) : Safety (S), Risky (R)

Table 7, shows all probability all conditions of nodes B, C, and $\mathrm{D}$ along with their child node $\mathrm{A}$, related to the second sub tree:

\begin{tabular}{|c|c|c|c|c|}
\hline \multicolumn{5}{|c|}{$\mathrm{P}(\mathrm{A} \mid \mathrm{B}, \mathrm{C}, \mathrm{D})$} \\
\hline $\mathrm{B}$ & $\mathrm{C}$ & $\mathrm{D}$ & $\mathrm{S}$ & $\mathrm{R}$ \\
\hline $\mathrm{S}$ & $\mathrm{S}$ & $\mathrm{S}$ & 0.9 & 0.1 \\
\hline $\mathrm{S}$ & $\mathrm{S}$ & $\mathrm{R}$ & 0.7 & 0.3 \\
\hline $\mathrm{S}$ & $\mathrm{R}$ & $\mathrm{S}$ & 0.7 & 0.3 \\
\hline $\mathrm{S}$ & $\mathrm{R}$ & $\mathrm{R}$ & 0.5 & 0.5 \\
\hline $\mathrm{R}$ & $\mathrm{S}$ & $\mathrm{S}$ & 0.7 & 0.3 \\
\hline $\mathrm{R}$ & $\mathrm{S}$ & $\mathrm{R}$ & 0.5 & 0.5 \\
\hline $\mathrm{R}$ & $\mathrm{R}$ & $\mathrm{S}$ & 0.5 & 0.5 \\
\hline $\mathrm{R}$ & $\mathrm{R}$ & $\mathrm{R}$ & 0.1 & 0.9 \\
\hline
\end{tabular}

Table 7. The CPT for Building_Interior_Evacuation_Rate

Flow capacity: The value of this node is determined by considering two children nodes, (i.e., Exit doors flow safety rate, and Normal flow safety rate). The value of exit doors flow safety is determined by the values of total number and average width of exit doors nods. Having more emergency exit doors inside public are proportionzal to having a higher value for total number of exit doors, which shows a higher safety. The average width of exit doors value rises with exit doors with more width in public space.

Normal flow safety rate: Determining the value of this node is similar to exit doors flow safety rate node. It has two child nodes, Number of interior doors, and Average width of interior doors. Based on the value of these nodes, the parent node vlaue (Normal flow safety rate) is determined.

Having two values for exit doors and all other type of interior doors helps us obtain the value of the parent node flow capacity. The value rate starts from 0 , which is used when there is a higher risky situation exists, to 100 which represents having no, or very low potential of risky status, regarding to flow safety rate node. If the public space has at least 2 exits, we assumed the node of Number_of_Exit_Doors, as safe. Also if there are at least 2 normal interior doors inside the space, we considered Number_of_Interior_Doors node value as safe.

Figure 8, shows this node with its child nodes as a BBN network pattern.

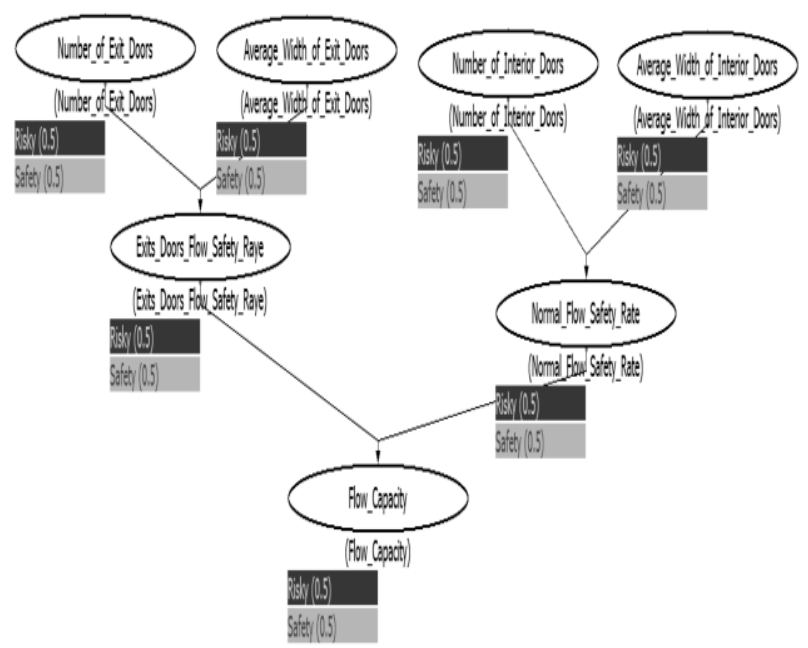

Figure 8. Flow capacity node, with its child nodes

In order to show conditional probability tables for figure 8 , we divided its BBN tree into three different sub trees, as follows:

Sub tree 1: (R)

- Exit_Doors_Flow_Safety_Rate (A) : Safety (S), Risky

- Number_of_Exit_Doors (B) : Safety (S), Risky (R)

- Average_Width_of_Exit_Doors (C) : Safety (S), Risky (R)

Table 8 , shows all probability all conditions of nodes B, C, and $\mathrm{D}$ along with their child node $\mathrm{A}$, related to the first sub tree:

\begin{tabular}{|c|c|c|c|}
\hline \multicolumn{4}{|c|}{$\mathrm{P}(\mathrm{A} \mid \mathrm{B}, \mathrm{C})$} \\
\hline B & $\mathrm{C}$ & $\mathrm{S}$ & $\mathrm{R}$ \\
\hline $\mathrm{S}$ & $\mathrm{S}$ & 0.9 & 0.1 \\
\hline $\mathrm{S}$ & $\mathrm{R}$ & 0.5 & 0.5 \\
\hline $\mathrm{R}$ & S & 0.5 & 0.5 \\
\hline $\mathrm{R}$ & $\mathrm{R}$ & 0.1 & 0.9 \\
\hline
\end{tabular}

Table 8. The CPT for Exits_Doors_Flow_Safety_Rate

Sub tree 2:

- Normal_Flow_Safety_Rate (A) : Safety (S), Risky (R)

- Number_of_Interior_Doors (B) : Safety (S), Risky (R) Risky (R)

- Average_Width_of_Interior_Doors (C) : Safety (S),

Table 9, shows all probability all conditions of nodes B, C, and $\mathrm{D}$ along with their child node $\mathrm{A}$, related to the second sub tree: 


\begin{tabular}{|c|c|c|c|}
\hline \multicolumn{4}{|c|}{$\mathrm{P}(\mathrm{A} \mid \mathrm{B}, \mathrm{C})$} \\
\hline $\mathrm{B}$ & $\mathrm{C}$ & $\mathrm{S}$ & $\mathrm{R}$ \\
\hline $\mathrm{S}$ & $\mathrm{S}$ & 0.9 & 0.1 \\
\hline $\mathrm{S}$ & $\mathrm{R}$ & 0.5 & 0.5 \\
\hline $\mathrm{R}$ & $\mathrm{S}$ & 0.5 & 0.5 \\
\hline $\mathrm{R}$ & $\mathrm{R}$ & 0.1 & 0.9 \\
\hline
\end{tabular}

Table 9. The CPT for Normal_Flow_Safety_Rate

Sub tree 3:

- Flow_Capacity (A) : Safety (S), Risky (R)

(R)

- Exit_Doors_Flow_Safety_Rate (B) : Safety (S), Risky

- Normal_Flow_Safety_Rate (C) : Safety (S), Risky (R)

Table 10, shows all probability all conditions of nodes B, $\mathrm{C}$, and D along with their child node A, related to the third sub tree:

\begin{tabular}{|c|c|c|c|}
\hline \multicolumn{4}{|c|}{$\mathrm{P}(\mathrm{A} \mid \mathrm{B}, \mathrm{C})$} \\
\hline $\mathrm{B}$ & $\mathrm{C}$ & $\mathrm{S}$ & $\mathrm{R}$ \\
\hline $\mathrm{S}$ & $\mathrm{S}$ & 0.9 & 0.1 \\
\hline $\mathrm{S}$ & $\mathrm{R}$ & 0.5 & 0.5 \\
\hline $\mathrm{R}$ & $\mathrm{S}$ & 0.5 & 0.5 \\
\hline $\mathrm{R}$ & $\mathrm{R}$ & 0.1 & 0.9 \\
\hline
\end{tabular}

Table 10. The CPT for Flow_Capacity

Space occupancy rate: This node shows the status of the type of crowd patterns that present people available into public place might form at any moment. If this value becomes 0 , it means having a risky banquets of crowd while having a higher value indicates a safer crowd gathering forms, and hence a safer environment, in terms of space occupancy rate. The value of this node depends of its two child nodes, Crowd occupancy arrangements, and Obstruction flow rate. Crowd occupancy arrangements node depends on its three child nodes including: Number of obstacles, Average size of obstacles, and Obstacle impasse rate. The values of these nodes are varying from 0 , which means a risky situation to 100 which indicates a safe status.

Obstruction flow rate: In some areas, based on their architecture, have a better talent to accept more people inside, such as a theater saloon, or a conference room. The assigned value to this node determines based on the talent of area, in order of the ability to accept the size of crowd inside. The value 0 shows having crowd in an inappropriate area, while having a higher value shows having a safer crowd forming inside.

Figure 9, shows the crowd density node with its child nodes in BBN network pattern.

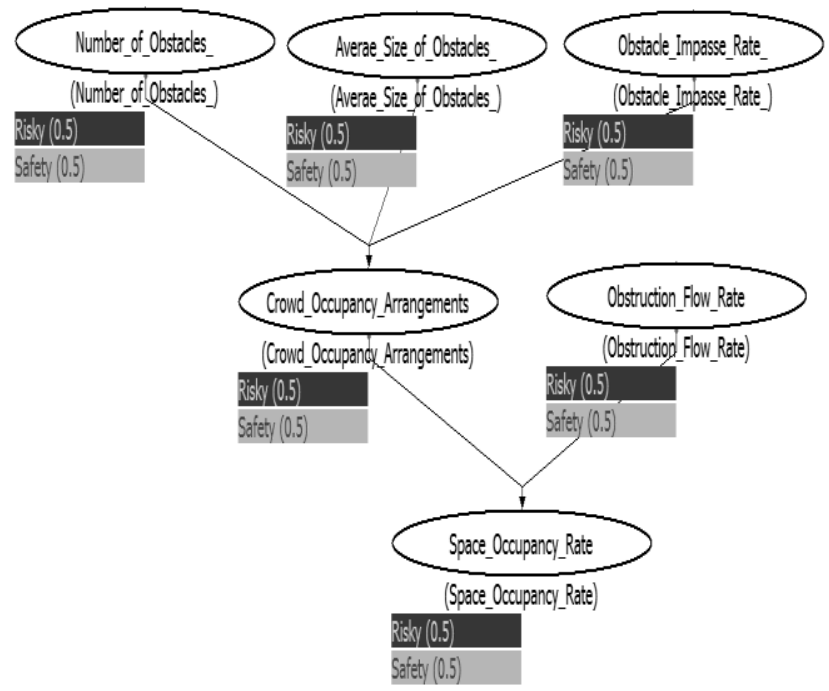

Figure 9. The Space occupancy rate node in BBN network

In order to show conditional probability tables for figure 9 , we divided its BBN tree into two different sub trees, as follows:

Sub tree 1:

- Crowd_Occupancy_Arrangements (A) : Safety (S), Risky (R)

- Number_of_Obstacles (B) : Safety (S), Risky (R)

- Average_Size_of_Obstacles (C) : Safety (S), Risky (R)

- Obstacle_Impasse_Rate (D) : Safety (S), Risky (R)

If different facilities available during any gathering occupied a space larger than $40 \%$, we classify Number_of_Obstacles as risky. If their sizes are large in average, or they are not properly installed inside the area, we considered the relevant nodes as risky.

Table 11, shows all probability all conditions of nodes B, $\mathrm{C}$, and D along with their child node A, related to the first sub tree:

\begin{tabular}{|c|c|c|c|c|}
\hline \multicolumn{5}{|c|}{$\mathrm{P}(\mathrm{A} \mid \mathrm{B}, \mathrm{C}, \mathrm{D})$} \\
\hline $\mathrm{B}$ & $\mathrm{C}$ & $\mathrm{D}$ & $\mathrm{S}$ & $\mathrm{R}$ \\
\hline $\mathrm{S}$ & $\mathrm{S}$ & $\mathrm{S}$ & 0.9 & 0.1 \\
\hline S & S & R & 0.7 & 0.3 \\
\hline S & R & S & 0.7 & 0.3 \\
\hline S & R & R & 0.5 & 0.5 \\
\hline R & S & S & 0.7 & 0.3 \\
\hline R & S & R & 0.5 & 0.5 \\
\hline R & R & S & 0.5 & 0.5 \\
\hline R & R & R & 0.1 & 0.9 \\
\hline
\end{tabular}

Table 11. The CPT for

Crowd_Occupancy_Arrangements node

Sub tree 2:

- Space_Occupancy_Rate (A) : Safety (S), Risky (R) 

Risky (R)

- Crowd_Occupancy_Arrangements (B) : Safety (S),

- Obstruction_Flow_Rate (C) : Safety (S), Risky (R)

Table 12, shows all probability all conditions of nodes B, $\mathrm{C}$, and $\mathrm{D}$ along with their child node $\mathrm{A}$, related to the third sub tree:

\begin{tabular}{|c|c|c|c|}
\hline \multicolumn{4}{|c|}{$\mathrm{P}(\mathrm{A} \mid \mathrm{B}, \mathrm{C})$} \\
\hline $\mathrm{B}$ & $\mathrm{C}$ & $\mathrm{S}$ & $\mathrm{R}$ \\
\hline $\mathrm{S}$ & $\mathrm{S}$ & 0.9 & 0.1 \\
\hline $\mathrm{S}$ & $\mathrm{R}$ & 0.5 & 0.5 \\
\hline $\mathrm{R}$ & $\mathrm{S}$ & 0.5 & 0.5 \\
\hline $\mathrm{R}$ & $\mathrm{R}$ & 0.1 & 0.9 \\
\hline
\end{tabular}

Table 12. The CPT for Space_Occupancy_Rate

Structural integrity: If the examined building generates with a standard and newly made materials, the child node, material used, has a higher value which indicates more safety. In this case, we assumed a building which is made by concrete or newly made materials, as a safe value. If the building is built in recent years, the relative node owes a higher value which indicates more safety comparing to an old aged build construction that represents a risky situation by showing a lower rate for its relative nodes. If the building has been built before 1950, we assumed this node as a risky node. Based on the values of two child nodes including: Material used and Structure age, the value of the parent node, Structural integrity, obtains. Figure 10, presents this node, as well as its child nodes in a BBN network pattern.

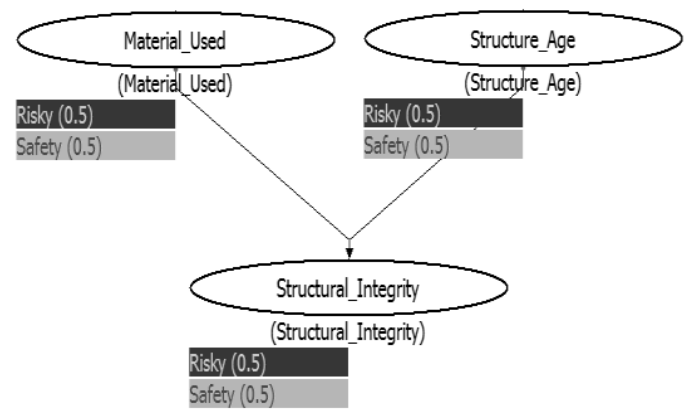

Figure 10. BBN tree for structural integrity node

- Structural_Integrity (A) : Safety (S), Risky (R)

- Material_Used (B) : Safety (S), Risky (R)

- Structure_Age (C) : Safety (S), Risky (R)

Table 13, shows all probability all conditions of nodes B and $\mathrm{C}$ along with their child node $\mathrm{A}$.

\begin{tabular}{|c|c|c|c|}
\hline \multicolumn{4}{|c|}{$\mathrm{P}(\mathrm{A} \mid \mathrm{B}, \mathrm{C})$} \\
\hline B & $\mathrm{C}$ & $\mathrm{S}$ & $\mathrm{R}$ \\
\hline $\mathrm{S}$ & $\mathrm{S}$ & 0.9 & 0.1 \\
\hline $\mathrm{S}$ & $\mathrm{R}$ & 0.5 & 0.5 \\
\hline $\mathrm{R}$ & $S$ & 0.5 & 0.5 \\
\hline $\mathrm{R}$ & $\mathrm{R}$ & 0.1 & 0.9 \\
\hline
\end{tabular}

Table 13. The CPT for Structural_Integrity node

First aid recovery capacity: Having a more rate for this node shows a safer and more stable situation. The average amount of two child nodes including number of installed safety tools and location of installed safety tools, determine the value of this node. If this node owes a lower value, it means we have no suitable or proper risk avoidance tools existing or installed inside space while a higher rate shows a safer place in terms of availability of such a tools located in proper locations. If there was no any of such tools available, or they are not installed at a proper location, we consider the relevant nodes as risky. Figure 11, shows this node, with its child nodes.

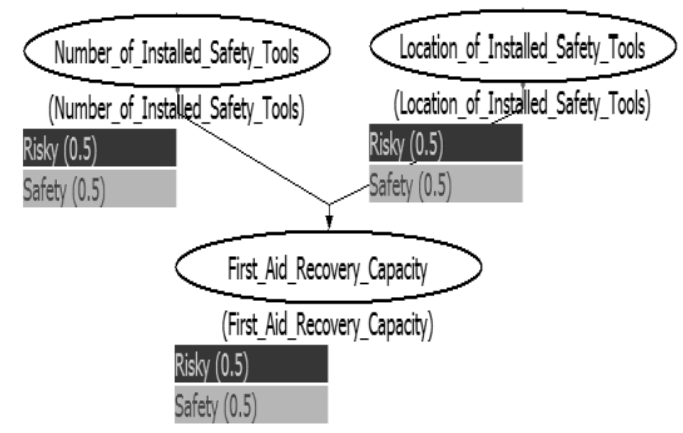

Figure 11. First aid recovery capacity in BBN network (R)

- First_Aid_Recovery_Capacity (A) : Safety (S), Risky Risky (R)

- Number_of_Installed_Safety_Tools (B) : Safety (S), - Location_of_Installed_Safety_Tools (C) : Safety (S),
Risky (R)

Table 14, shows all probability all conditions of nodes B and $\mathrm{C}$ along with their child node $\mathrm{A}$.

\begin{tabular}{|c|c|c|c|}
\hline \multicolumn{4}{|c|}{$\mathrm{P}(\mathrm{A} \mid \mathrm{B}, \mathrm{C})$} \\
\hline B & $\bar{C}$ & $\mathrm{~S}$ & $\mathrm{R}$ \\
\hline$S$ & $S$ & 0.9 & 0.1 \\
\hline $\mathrm{S}$ & $\mathrm{R}$ & 0.5 & 0.5 \\
\hline $\mathrm{R}$ & $\mathrm{S}$ & 0.5 & 0.5 \\
\hline $\mathrm{R}$ & $\mathrm{R}$ & 0.1 & 0.9 \\
\hline
\end{tabular}

Table 14. The CPT for First_Aid_Recovery_Capacity

Crowd properties: This node as a parent node has two child nodes as follows: Movement rate: This node has two 
other child nodes itself including: Age category, and Health status. If the average age of the present people in public space is between 15 and 50 years old, this node has a safe value which means the best ability of the crowd inside to move quickly and keep them out of danger in a short period of time. If the average health status of the people inside is unhealthy, such as studding on a hospital, the node of health status will have a risky value, which indicates the lacking ability of people inside to evacuate from public space in case of having any emergencies, in a reasonable amount of time. With having the age category and average health status nodes, we are able to estimate their parent node, movement rate.

Crowd distribution pattern: In a theater saloon, we observe having a normal rate for distribution of people most of time, while for example, in a sport saloon, crowd move randomly with a pattern which changes randomly at any moment. This node determines distribution rate of people inside a public space. Considering gathering pattern is important, especially when all such patterns decide to evacuate at a same time. In such cases, we observe having herding, pushing which may cause to injury people while evacuating. A larger number for this node indicates, more distributed crowd pattern inside the environment and hence a more safe status, while having a lower rate shows having a potential risk when placing in any dangerous situations, that leads evacuating people from inside in a short period of time.

The crowd properties node determines based on its child nodes movement rate and crowd distribution pattern values. If this nodes value is lower than 50 , it means having a more risky situation, while the value of 50 or greater, shows a safer situation. Figure 12, shows this node with all its child nodes on a BBN pattern.

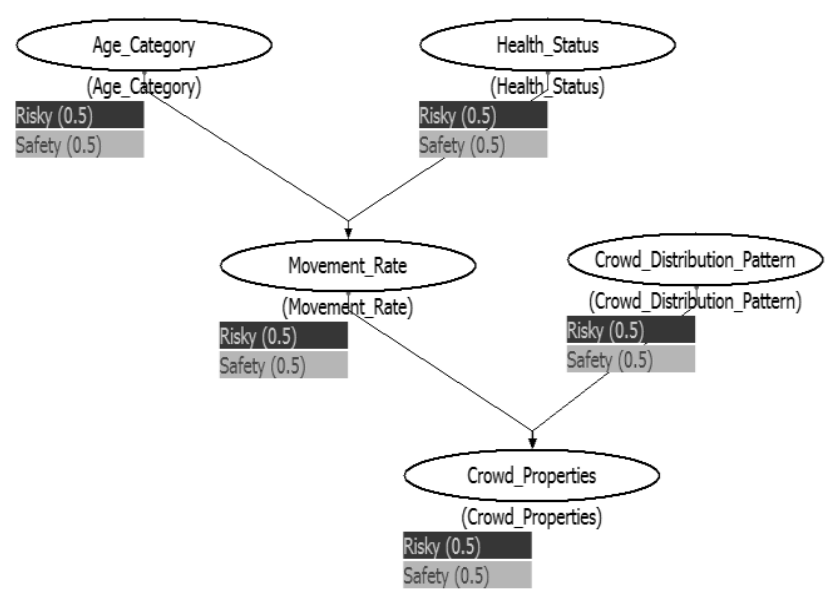

Figure 12. BBN tree for crowd properties node

In order to show conditional probability tables for figure 9, we divided its $\mathrm{BBN}$ tree into two different sub trees, as follows:

\section{Sub tree 1:}

- Movement_Rate (A) : Safety (S), Risky (R)
- Age_Category (B) : Safety (S), Risky (R)

- Health_Status (C) : Safety (S), Risky (R)

Table 15 , shows all probability all conditions of nodes $\mathrm{B}$ and $\mathrm{C}$ along with their child node $\mathrm{A}$.

\begin{tabular}{|c|c|c|c|}
\hline \multicolumn{4}{|c|}{$\mathrm{P}(\mathrm{A} \mid \mathrm{B}, \mathrm{C})$} \\
\hline B & $\mathrm{C}$ & $\mathrm{S}$ & $\mathrm{R}$ \\
\hline $\mathrm{S}$ & $S$ & 0.9 & 0.1 \\
\hline$S$ & $\mathrm{R}$ & 0.5 & 0.5 \\
\hline $\mathrm{R}$ & $\mathrm{S}$ & 0.5 & 0.5 \\
\hline $\mathrm{R}$ & $\mathrm{R}$ & 0.1 & 0.9 \\
\hline
\end{tabular}

Table 15. The CPT for Movement_Rate

Sub tree 2:

- Crowd_Properties (A) : Safety (S), Risky (R)

- Movement_Rate (B) : Safety (S), Risky (R)

- Crowd_Distribution_Pattern (C) : Safety (S), Risky (R)

Table 16, shows all probability all conditions of nodes B and $\mathrm{C}$ along with their child node $\mathrm{A}$.

\begin{tabular}{|c|c|c|c|}
\hline \multicolumn{4}{|c|}{$\mathrm{P}(\mathrm{A} \mid \mathrm{B}, \mathrm{C})$} \\
\hline B & $\mathrm{C}$ & $\mathrm{S}$ & $\mathrm{R}$ \\
\hline $\mathrm{S}$ & S & 0.9 & 0.1 \\
\hline$S$ & $\mathrm{R}$ & 0.5 & 0.5 \\
\hline $\mathrm{R}$ & $\mathrm{S}$ & 0.5 & 0.5 \\
\hline $\mathrm{R}$ & $\mathrm{R}$ & 0.1 & 0.9 \\
\hline
\end{tabular}

Table 16. The CPT for Crowd_Properties

Public safety: This node as a root node of the building safety Bayesian belief network structure has two general child nodes itself, including: Crowd properties, and Physical properties. The value of this node depends on the overall values of two other mentioned child nodes. Having a value greater than 60, indicates that the examined building has enough safety to accept the expected people inside, while having a value below that 60 , shows a risky situation and represent that the examined public place is not proper to accept the expected people inside. In such cases, either changing the area of the public space or increasing the safety of the building by increasing the amount of each parent nodes as well as their child nodes is essential. If the total value for all of its parents is $60 \%$ or less we considered the situation to be risky for the child nodes. If all its relevant parents are totally greater than $60 \%$ of safety, a node is considered to be safe.

\section{VALIDATION AND EXPERIMENTAL RESULTS}

Experimental setup 1

In this section we duplicated the Ballroom $D$ of the Student Center located in Southern Illinois University at Carbondale (SIUC). Student center contains four floors and the Ballroom D is one of its public spaces, which is located at the second floor. Figure 13 shows the plan of the second floor, 
including Ballroom D.

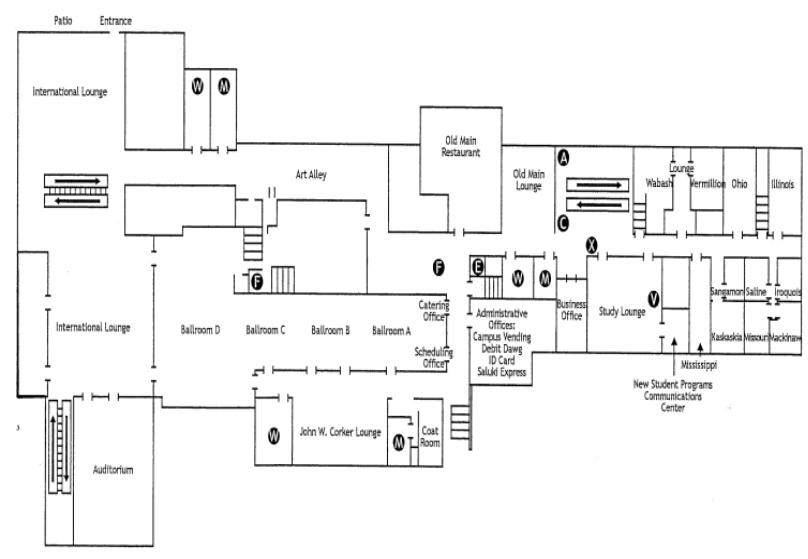

Figure 13. Ballroom D of the SIUC. (Adopted from a local university map)

Based on the initial values of BBN tree, we will examine this place to explore the rate of safety for it. Following are different needed details of this public space, as well as the safety rates referring to the CPTs of each:

During events, the remaining empty space between the indoor and the exterior building entrance door is about $40 \%$ of the whole available area. The average size of obstacles occupied is about $50 \%$ empty space, and they are distributed normally to the available space. Based on table 4 , we consider both values for nodes $\mathrm{B}$, and $\mathrm{C}$, as safety and hence, the obstacle node value becomes 0.9 or $90 \%$, which is classified as a safety situation.

Student center has 4 floors, which will be classified as a multilevel building. Because ballroom $\mathrm{D}$ is located at the second floor, the value of the Type_Of_Building node becomes as $R$, which represents Risky. The floor level vertical distance is classified as $R$ as well. Referring table 5, the Building_Perimeter_Evacuation_Rate, classifies as a safety node, with having a 50\% chance of safety. In terms of considering indoor space, during events, there are about 50\% space is occupied by different obstacles with the average size of $50 \%$ that are installed with a normal distribution. Regarding table 6 , the obstacles node indicates safety value. There are also 2 exit doors as well as 2 normal entrance doors available inside the space. The values of nodes Total_Number_of_Exit_Doors and Total_Number_of_Normal_Doors, hence become as safe. Regarding to table 7, the Building_Interior_Evacuation_Rate node has a safe value, with having a $90 \%$ chance of safety. Table 3, indicates a safe node for overall exit capacity, based on the situation of its other parent nodes that we obtained previously. This node has a safety rate of $90 \%$.

Based on the total number of exit doors and their width, as well as the number of normal interior doors, referring tables 8, and 9, exit doors Flow_Safety_Rate and Normal_Flow_Safety_Rate are classified as a safe nodes and hence, regarding table 10, the IO_Safety_Rate shows a safe value, based on its parent nodes. This node has a chance of
90\% for safety. There is no first aid recovery tools installed inside the public area. The Number_of_Installed_Safety_Tools node as well as location both on table 14 will be set as risky, consequently. As a result of parent nodes, First_Aid_Recovery_Capacity node becomes as $R$ which indicates as a risky situation for this part of the BBN tree. In this case, this node has only a $10 \%$ chance of safety. During a usual gathering, the installed facilities, such as chairs, the available empty space is less than $30 \%$ of the whole available area. Based on the number of facilities installed inside the area, as well as their position, followed by their average of size, regarding to table 11, the Crowd_Occupancy_Arrangements node becomes risky. The average size and installed positions are both will set to safety. This leads the Obstruction_Flow_Rate node becomes as a safe node with having a $70 \%$ chance of safety. This place is built for gathering purposes with having enough space inside. Because of that, we classified the Crowd_Occupancy_Arrangements as a safe node. Having the values of both nodes Obstruction_Flow_Rate and Crowd_Occupancy_Arrangements nodes values are based on table 12, leads us having the Space_Occupancy_Rate as a safety value with having a $90 \%$ chance of safety. Based on the area yearly average weather status, this area is located to a windy/stormy position for most days of the year, so we will classify the Weather_Instability_Sources node as a risky situation. The distance from this area and the train rails is less than 3 kilometers; hence, we considered a risky value for Manmade_Instability_Sources node. The building is far enough from any earth faults or mountains with having volcanoes; hence, we considered the value of the Terrian_Instability_Sources as a safe node. Regarding to table 2, and based on the values of parent nodes, Terrestrial_Sustainability value becomes safety with having a $50 \%$ chance of safety. The majority building is built by concrete, which cause to show safety for node Material_Used. It built on 1925, so the Structural_Age will be set as risky value. Referring table 13, the value of Structural_Integrity becomes as safe with having a 50\% chance of safety. Usually, the majority age for the present people, is between 15 and 50 years old. The majority health status is also healthy for the people who gathered inside this place. Based on the classifications that already discussed on the relevant section, the values of both Age_Category and Health_Status nodes become as a safe value. Having parent nodes, regarding table 15, the child node Movement_Rate becomes as a safe situation consequently. It has a $90 \%$ chance of safety. When forming a crowd, they usually have a $50 \%$ distribution on the whole available area which means a normal distribution. The Crowd_Distribution_Pattern node, hence, shows a safe value with having a $90 \%$ chance of safety. Referring table 16, and based on the parent nodes of the Crowd_Properties node, it presents a safety value, having a $90 \%$ chance of safety. Regarding diagram 1 and based on the values for parent nodes of the Physical_Properties node, it shows a safety value, having a $90 \%$ chance of safety. By determining the final measurement regarding table 1 and based on the values of 
parent nodes Physica_Properties and Crowd_Properties, the value of the child node Public_Safety node will be determine. This node reflects a safety measure, having a $90 \%$ chance of safety.

\section{Experimental setup 2}

In contrast to our first experiment, our second experiment exhibits a contradictory instance for our protocol. We considered the Hyatt regency walkway located in Hyatt regency Kansas City in Kansas City, Missouri. In Kansas City the walkway collapsed and fell two connected walkways while they are occupied with a large group of attendance in the lobby holding a tea dance area below. It caused over 114 people to lose their lives and more than 216 other people to be injured. The incident occurred in July 17, 1981 and it was known as the deadliest structural collapse in U.S. history until 2001, when the buildings of world trade center collapsed due to the infamous $9 / 11$ terrorist attacks. We applied our model to the Hyatt building for the purpose of validating our model. It demonstrates dangerous and unreliable situations for that building based on available specifications related to it. Considering people as obstacles since a large group of people were attending that building most of the times. Therefore obstacle nodes show a risky situation. The nodes of Type_of_Building and Floor_Level are both risky based on the building specification and hence Building_Preimeter_Evacuation_Rate is determined to be risky. The only way to reach the exit doors were located at two sides if the hallways. Consequently, Building_Interior_Evacuation_Rate which depends on obstacles and total number of exit and normal doors is considered risky. As a result, Overal_Exit_Capacity is risky. The Flow_Capacity node shows a risky situation because all its children nodes are indicating risky situations. The Space_Occupancy_Rate is risky because of the large number of people who were present in the building most of times. Since the hallways were not equipped with proper numbers of first aid recovery tools and hence the relevant nodes are risky. Two nodes of Terrestrial_Sustainability and Structural_Integrity exhibit safety because there were not major sources of vibrating sources around the building and also the building collapsed shortly after opening to the people. Figure 14 shows the earthquakes status around Kansas City.

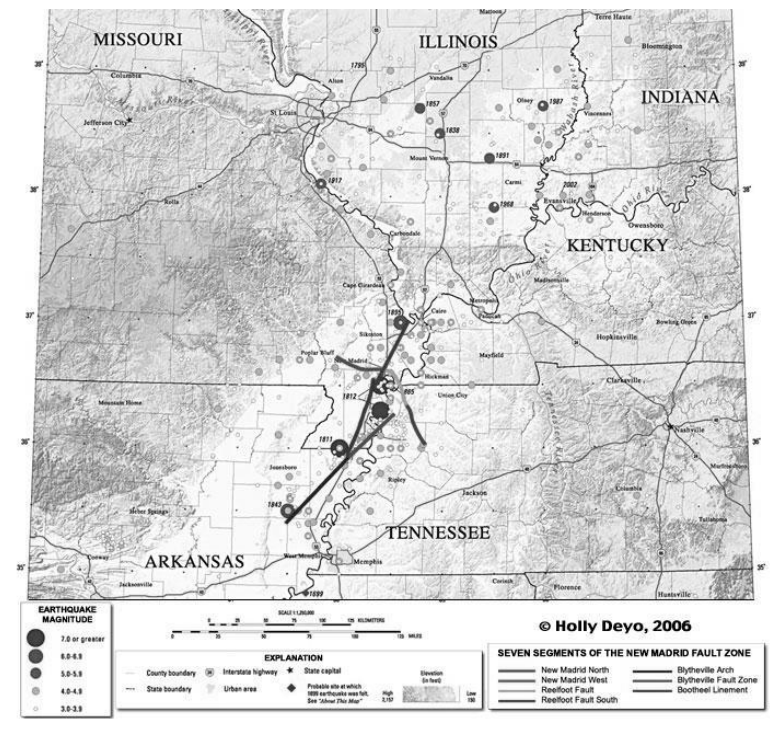

Figure 14. Earthquakes status around Kansas City Adapted from www.greatdreams.com/madrid.htm

Regarding to diagram 1 , since we have 4 risky and 2 safe situations, the status for the Physical_Properties node becomes risky with $70 \%$ chance of risky. The Age_Category node is

risky, however the Health_Status node is safe, and the

Movement_Rate node value becomes safety with 50\% chance of safety. The Crowd_Distribution_Pattern node is risky,

because there was no any particular arrang ement among the people who were present at the hallways. The

Crowd_Properties node is safe with the $50 \%$ chance of safety.

In this case, because the other major node (i.e.,

Physical_Properties) has a $70 \%$ chance of lack of safety, the final result of the building safety is determined to be risky.

\section{CONSTRUCTING OF BAYESIEN BELIEF NETWORKS}

This paper employed Bayesian belief networks as the computational mechanism for evaluating potential risks that can be determined from unpredictable patterns of crowd movements in a building. Using Bayesian belief network as a tool we are able to predict the probability of building faults from a large group of people. We focused on pertinent attributes of the environment and the people contributing to potential risks. It is essential to have such a mechanism wherever a large group of people congregate in indoor public spaces especially when the space is located on upper levels of the building. This will help security personnel to determine strategies for guiding people to safety. This can prevent potential risk that can occur due to movements in emergencies from damage from excess weight on structures.

\section{REFERENCES}

[1] Barnett, G. O., Famiglietti, K T., Kim, R. J., Hoffer, E. P., Feldman, M.J., 1998. DXplain on the Internet. In American Medical Informatics Association 1998 Annual Symposium.

[2] Bellomo, N., Dogbe, C., (2011), "On the Modeling of Traffic and Crowds: A Survey of Models, Speculations, and Perspectives", In SIAM REVIEW c 2011 Society for Industrial and Applied Mathematics, Vol. 
53, No. 3, pp. 409-463, Society for Industrial and Applied Mathematics pub.

[3] Berler, A., Shimony, S.E., (1997), "Bayes Networks for Sonar Sensor Fusion", In Geiger, D, Shenoy, P (eds) 1997. Proceedings of the Thirteenth Conference on Uncertainty in Artificial Intelligence Morgan Kaufmann.

[4] Colombo, R., Goatin, P., Rosini, M., (2010), "A Macroscopic Model of Pedestrian Flows in Panic Situations", In Current Advances in Nonlinear Analysis and Related Topics, pp.43-60, Mathematical Sciences and Applications, Gakuto Pub.

[5] Cooper, G.F., (1984), "NESTOR: A computer-based medical diagnostic aid that integrates causal and probabilistic knowledge", In Ph.D. dissertation, Medical Information Sciences, Stanford University.

[6] Cooper, G.F., (1987), "Probabiistic inference using belief networks is NP-hard", In Technical Report KSL-87-27, Medical Computer Science Group, Stanford University.

[7] Cooper, G.F., Herskovits, E., (1992), "A Bayesian Method for the Induction of Probabilistic Networks from Data", In Machine Learning Vol. 9 pp. 309-347.

[8] Davies, T.R., Russell, S.J., (1987), “A logical approach to reasoning by analogy”, In IJCAI 10 (pp. 264-270).

[9] Dempster, A.P., Laird, N.M., Rubin, D.B., (1977), "Maximum Likelihood from Incomplete Data via the EM Algorithm with discussion", In Journal of the Royal Statistical Society, Series B, Vol. 39 pp.1-38.

[10] Dogbe, C., (2010), "On the Cauchy problem for macroscopic model of pedestrian flows", In J. Math. Anal. Appl. 372, (2010), 77-85, Elsevier pub.

[11] Duda, R.O., Hart, P.E., Nilsson, N.J., (1976), "Subjective Bayesian methods for rule-based inference systems", In Proceedings of the 1976 National Computer Conference (AFIPS Press), pp. 1075-1082.

[12] Etxeberria, R., Larranaga, P., Pikaza, J.M., (1997), "Analysis of the behaviour of the genetic algorithms when searching Bayesian networks from data", In Pattern Recognition Letters Vol. 18 No 11-13 pp 12691273

[13] Ezawa, K.J., Schuermann, T., (1995), "Fraud/Uncollectible Debt Detection Using a Bayesian Network Based Learning System: A Rare Binary Outcome with Mixed Data Structures", In Besnard, P, Hanks, S (eds) Proceedings of the Eleventh Conference on Uncertainty in Artificial Intelligence Morgan Kaufmann.

[14] Frey, B.J., (1998), "Graphical Models for Machine Learning and Digital Communication", In MIT Press.

[15] Friedman, N., (1998), "The Bayesian Structural EM Algorithm", In Cooper, GF, Moral, S (eds) Proceedings of the Fourteenth Conference on Uncertainty in Artificial Intelligence Morgan Kaufmann.

[16] Gawronski, P., Kulakowski, K., (2011), "Crowd dynamics - being stuck", In Computer Physics Communications Vol. 182, No. 9, pp. 1924-1927.

[17] Good, I.J., (1961-62), “A causal calculus (I \& II)”, In British Journal of the Philosophy of Science 11: 305-318 12: 43-51.

[18] Helm, L., (1996), " Improbable Inspiration", In Los Angeles Times, October 28, 1996.

[19] Henein, C., White, T., (2010), "Microscopic information processing and communication in crowd dynamics", In Physica A(389), pp. 4636-4653, Elsevier Pub.

[20] Howard, R.A., Matheson, J.E., (1984), "Influence Diagrams", In Howard, R.A. and Matheson, J.E. (eds.), The Principles and Applications of Decision Analysis, (Strategic Decisions Group, Menlo Park, CA), pp. 721-762.

[21] Jensen, F.V., (1996), “An Introduction to Bayesian Networks”, In UCL Press.

[22] Jiang, Y., Zhang, P., Wong, S.C., Liu, R., (2010), "A higher-order macroscopic model for pedestrian flow", In Physica A: Statistical Mechanics and its Applications, Volume 389, Issue 21, 1 November 2010, Pages 4623-4635, Elsevier pub.
[23] Korhonen, T., Heliovaara, S., Hostikkaa, S., Ehtamo, H., (2010). "Counterflow Model for Agent-Based Simulation of Crowd Dynamics", In Safety Science.

[24] Krause, P., Clark, D., (1993), "Representing Uncertain Knowledge: An Artificial Intelligence Approach", In Intellect Books.

[25] Larranaga, P., Kuijpers, C.M.H., Murga, R.H., Yurramendi, Y., (1996), "Learning Bayesian network structures by searching for the best ordering with genetic algorithms", In IEEE Trans on Systems, Man and Cybernetics-A Vol. 26 No. 4 pp.487- 493.

[26] Lauritzen, S.L., Spiegelhalter, D.J., (1988), "Local computations with probabilities on graphical structures and their application to expert systems", In Journal of the Royal Statistical Society, Vol. 50 No. 2 pp.157-224.

[27] Lauritzen, S.L., Wermuth, N., (1989), "Graphical models for associations between variables, some of which are qualitative and some quantitative", In Annals of Statistics 17, 31-57.

[28] Mitchell, T.M., (1997), "Machine Learning”, In McGraw-Hill.

[29] Narendra, P.M., Fukunaga, K., (1977), "A Branch and Bound Algorithm for Feature Subset Selection", In IEEE Transactions on Computers, Vol. 26, No. 9, pp. 917-922.

[30] Neil, M., Littlewood, B., Fenton, N., (1996), "Applying Bayesian Belief Networks to Systems Dependability Assessment", In Proceedings of Safety Critical Systems Club Symposium, Leeds, 6-8 February 1996 Springer-Verlag.

[31] Patil, S., Van den Berg, J., Curtis, S., Lin, M., Manocha, D., (2011), "Directing Crowd Simulations Using Navigation Fields", In IEEE Transactions on Visualization and Computer Graphics, vol. 17(2), pp. 244-254, IEEE press.

[32] Pearl, J., (1986), "Fusion, propagation and structuring in belief networks", In Artificial Intelligence 29 241-288.

[33] Pearl, J., (1988), "Probabilistic Reasoning in Intelligent Systems: networks of plausible inference", In Morgan Kaufmann.

[34] Peacock, R.D., Kuligowski, E.D., Averill, J.D., (Eds), (2011), "Pedestrian and Evacuation Dynamics", In Springer pub.

[35] Pires, T.T., 2005. An approach for modeling human cognitive behavior in evacuation models, In Fire Safety Journal, Vol. 40, No. 2, March 2005, Pages 177-189, Elsevier Pub.

[36] Rousseau, W.F., (1968), “A method for computing probabilities", In complex situations, Technical Report 6252-2, Stanford University Center for Systems Research.

[37] Shachter, R.D., (1986), "Intelligence Probabilistic inference", In Kanal, L.N., Lemmer, J.F. (eds.), Uncertainly in Artificial Intelligence (NorthHolland, Amsterdam), pp. 371-382.

[38] Shendarkarb, A., Vasudevana, K., Leea, S., Son, Y., 2008. Crowd simulation for emergency response using BDI agents based on immersive virtual reality, Simulation Modeling Practice and Theory, Vol. 16, No. 9, Pages 1415-1429, Elsevier Pub.

[39] Shiwakoti, N., Sarvi, M., Rose, G., Burd, M., (2011), "Animal dynamics based approach for modeling pedestrian crowd egress under panic conditions", In Transpostation Research B, pp. 1-17, Elsevier Pub.

[40] Steffen, B., Seyfried, A., (2010), "Methods for measuring pedestrian density, flow, speed and direction with minimal scatter", In Physica A 389, pp. 1902-1910, Elsevier.

[41] Trautman, P., Krause, A., 2010. Unfreezing the Robot: Navigation in Dense, Interacting Crowds, IROS proceedings, pp. 797-803, IEEE press.

[42] Weiss, S.M., Kulikowski, C.A., Amarel, S., Safir, A., (1978), "A modelbased method for computer-aided medical decision making", In Artificial Intelligence 11 145-172.

[43] Zheng, X., Cheng, Y., (2011), "Modeling cooperative and competitive behaviors in emergency evacuation: A game-theoretical approach", In Computers \& Mathematics with Applications, Vol. 62, No. 12, p. 46274634, Elsevier. 